\title{
Improvements in Diabetic Patients' Outcomes in a Clinical Decision Support System
}

\author{
Sakiko Ota ${ }^{1^{*}}$, Kaoru Mogushi ${ }^{2,3}$, Aizan Hirai ${ }^{4}$, Yoshihito Niimura ${ }^{1,5}$ and Hiroshi Tanaka ${ }^{2,6,7}$ \\ ${ }^{1}$ Graduate School of Medical and Dental Sciences, Tokyo Medical and Dental University, Tokyo, Japan \\ ${ }^{2}$ Medical Research Institute, Tokyo Medical and Dental University, Tokyo, Japan \\ ${ }^{3}$ Intractable Disease Research Center, Graduate School of Medicine, Juntendo University, Tokyo, Japan \\ ${ }^{4}$ Chiba Prefectural Togane Hospital, Chiba, Japan \\ ${ }^{5}$ Graduate School of Agricultural and Life Sciences, The University of Tokyo, Tokyo, Japan \\ ${ }^{6}$ Division of Medical Data Science, Tokyo Medical and Dental University, Tokyo, Japan \\ ${ }^{7}$ Tohoku Medical Megabank Organization, Tohoku University, Sendai, Japan
}

\begin{abstract}
Background: There is considerable interest worldwide in prevention and control of diabetes using health information technology systems. Although previous studies have acknowledged improvements of blood pressure control in a clinical decision support system (CDSS), little is known about whether it could contribute to diabetic patients outcomes.
\end{abstract}

Objectives: To compare diabetic patients' outcomes six months before and after the introduction of a CDSS.

Methods: We considered patients with diabetes in a general hospital and ten clinics that embedded a CDSS within an electronic health record in April 2011, and tracked their medical records from October 2010 to March 2012 (split at April 2011; pre- and post-period). The CDSS mainly had two main functions: (1) to visually highlight abnormal laboratory values on longitudinal inspection data; and (2) to provide a list of patients with severe diabetes. Primary outcome measures included glycated hemoglobin (HbAlc), fasting blood glucose, low-density lipoprotein cholesterol (LDL-C), and glomerular filtration rate (eGFR). The values were averaged for each patient and compared between preand post-period using the Wilcoxon signed-rank test.
Results: A total number of 3,678 blood test results from 705 patients were analyzed. The mean HbAlc levels (and standard deviation) among severe cases (baseline $\mathrm{HbAlc}$ $\geq 8.4 \%$ ) were significantly improved over the study period, from $9.49 \pm 1.13 \%$ to $8.73 \pm 1.23 \%(p<0.001)$. In contrast, the moderate group (baseline HbAlc $<8.4 \%$ ) deteriorated, from $7.61 \pm 0.40 \%$ to $7.70 \pm 0.65 \%$. In terms of fasting blood glucose levels, the severe group (baseline fasting blood glucose level $\geq 160 \mathrm{mg} / \mathrm{dl})$ improved significantly $(\mathrm{p}<0.001)$. On the contrary, the moderate group (baseline fasting blood glucose level $<160 \mathrm{mg} / \mathrm{dl}$ ) deteriorated significantly ( $\mathrm{p}<$ 0.001 ). The patients' outcomes were improved with the CDSS.

Conclusion: Improvements of patients' outcomes were observed, indicating the potential effectiveness of the CDSS. Visually emphasizing abnormal laboratory values and displaying severe patients may be effective for disease control of diabetes patients.

\section{Keywords}

Clinical decision support system; Community network; Diabetes mellitus; Electronic health record; Health information system

\section{Correspondence to:}

Dr. Sakiko Ota,

\section{Introduction}

\subsection{Background}

The number of people with diabetes mellitus has rapidly increased worldwide. The World Health Organization reported that an estimated 422 million adults worldwide were living with diabetes in 2014 [1]. In Japan, the number of patients with diabetes has increased from 2.70 million in 2011 to 3.17 million in 2014, according to a patient survey by the Ministry of Health, Labour and Welfare [2]. 
Establishing a HIT, such as an electronic health record (EHR) and a clinical decision support system (CDSS), is an important clinical and public health tactic $[3,4,5,6,7,8,9,10]$. One potential use of the HIT that has received growing attention is the prevention and control of non-communicable diseases (NCDs) such as diabetes $[11,12,13,14,15]$.

The Healthcare Information and Management Systems Society (HIMSS) defines clinical decision support as "a process for enhancing health-related decisions and actions with pertinent, organized clinical knowledge and patient information to improve health and healthcare delivery" [16]. To date, the CDSSs linked to EHRs play an important part in improving patient safety, efficiency of the healthcare delivery process, and quality of care.

A previous study indicated that the use of a CDSS was associated with improvement of blood pressure control [17]. Moreover, a CDSS integrated with EHRs could moderately improve the outcomes of morbidity [18]. However, little is known about whether CDSSs could contribute to diabetic patients outcomes [19, 20, 21].

The study aimed to compare patients' diabetes measures six months before and after the introduction of a CDSS. Firstly, we developed a CDSS, which was embedded in an EHR. Secondly, we conducted an experimental study in a general hospital and ten clinics that embedded the CDSS within EHRs.

Figure 1 depicts the structure of the regional EHR, "Wakashio medical network system," which uses the Internet protocol virtual private network (IP-VPN) and the hospital's local area network (LAN) to support collaboration across general practitioners and diabetes specialists in Togane area, Japan. Practitioners and diabetologists logged into the CDSS to see laboratory data (e.g., glycated hemoglobin [HbA1c], fasting blood glucose level, lowdensity lipoprotein cholesterol [LDL-C], estimated glomerular filtration rate $[e G F R]$ ), and comments by other providers when they see patients with diabetes. Figure 2 provides an overview of steps in the referral and counter referral with the CDSS. In the Togane area, diabetologists typically take charge of the patients with severe diabetes and general practitioners manage the patients with moderate diabetes. A local treatment guideline states that patients with diabetes should be referred to diabetologists when their glycated hemoglobin (HbAlc) values exceeded $8.4 \%$. We developed the CDSS to support physicians in noticing the deterioration of $\mathrm{HbA1c}$ values and in following the guideline, we developed the CDSS. The CDSS had two functions: (1) visually highlight abnormal laboratory values on longitudinal data (e.g., HbA1c, fasting blood glucose level, low-density lipoprotein cholesterol [LDL-C], and estimated glomerular filtration rate [eGFR]); and (2) to provide a list of patients with severe diabetes (i.e., HbAlc level $\geq 8.4 \%$ ).

\subsection{Overview of the "Wakashio Medical Network"}

The regional EHR system, known as the "Wakashio Medical Network", was developed at the Chiba Prefectural Togane

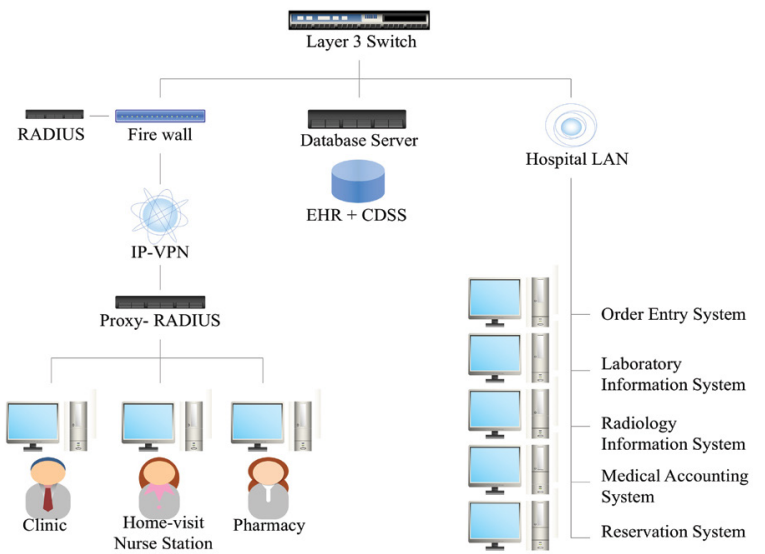

Figure 1: Structure of the Wakashio medical network. The structure of the medical network system for collaboration across general practitioners and diabetes specialists in the Togane area.

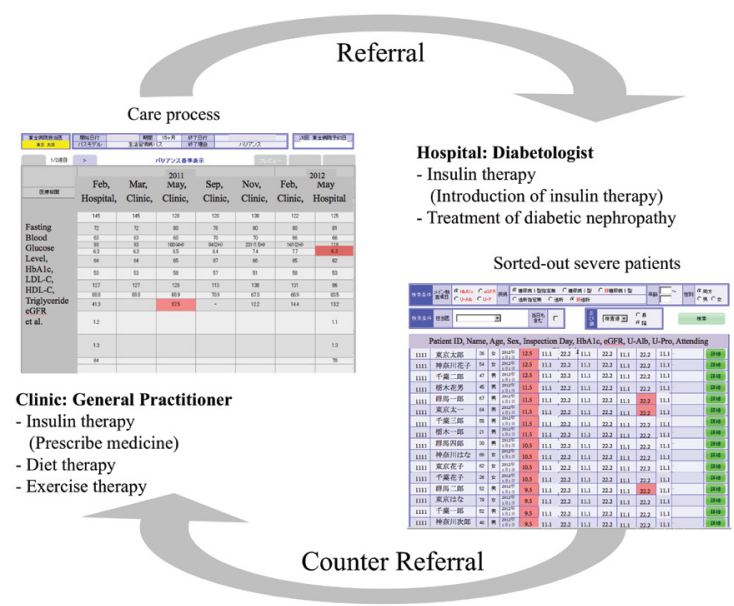

Figure 2: Outline of the medical collaboration with the CDSS. Overview of the steps in the referral and counter-referral among general practitioners and diabetologists with the CDSS. The main feature of the CDSS is to support general practitioners and diabetologists in noticing abnormal laboratory values.

Hospital, which is a 191-bed local hospital. The shared clinical data was used among general practitioners at 10 clinics and diabetologists at the hospital. The information items were based on Togane's dataset of diabetes care. The dataset included patients' $\mathrm{HbAlc}$, fasting blood glucose, LDL-C, and eGFR.

\subsection{Features of the CDSS}

The CDSS was developed in July 2010 in the EHR stepwise by April 2011. The system was designed in accordance with the clinical guidelines for treating diabetes in Japan [22, 23, 24]. The CDSS mainly had two functions: (1) visually highlight abnormal laboratory values on longitudinal inspection data (e.g., HbA1c, Fasting blood glucose level, and eGFR); and (2) to provide a list of patients with severe diabetes (e.g., HbA1c level $\geq 8.4 \%$ [8.0\%: Japan Diabetes Society (JDS)]). 
Thus, those with severe diabetes had more opportunities to be highlighted in the CDSS.

Both practitioners and diabetologists use the CDSS, such as the table of care process and the sorted-list of severe patients, when performing the examinations. In the table of the care process, it displays the longitudinal inspection data per patient and facilitates the recognition of abnormal laboratory values with pink highlighted color. In the sorted list of severe patients, it displays the basic information of severe patients and abnormal laboratory values are highlighted in pink.

\section{Materials and Methods}

\subsection{Study Design and Sample Size}

We conducted an empirical study in the general hospital and 10 clinics which used the CDSS embedded in EHRs. We compared diabetic patients' lab values six months before and after the introduction of the CDSS. The sample size calculation was made using $G^{*}$ Power version 3 software, which was developed at the Department of Psychology, Heinrich Heine University, Dusseldorf, Germany [25]. Type 1 error [ $\alpha=0.05$ (two-tailed)], power of 0.8 , and effect size of 0.3 were used to calculate the minimum sample size. As a result, at least 94 subjects were required. The distribution-based Minimal Clinically Important Difference (MCID) was estimated using the Cohen effect size benchmark. The effect size of 0.3 (i.e., 0.3 SD of the baseline score) indicated an important change and was used as the MCID in this study.

\subsection{Data Source}

We used data from EHRs in the Chiba Prefectural Togane Hospital, Japan. Participants in the study were selected based on the following criteria: (1) persons aged 20 years old or over; and (2) whose baseline of HbAlc level $\geq 6.9 \%$ (6.5\% JDS). Baseline or pre-intervention data were collected from October 1, 2010 to March 31, 2011. Twelve-month follow-up or post-intervention data were collected from October 1, 2011 to March 31, 2012. We excluded data between April 1 and September 30, 2011 to assess the impact on HbAlc levels, which identifies the average plasma glucose level over the preceding few months [26]. We conducted the study based on the 962 consecutively treated patients with diabetes between October 1, 2010 and March 31, 2012 in Togane area, Japan. Patients were excluded if they had laboratory tests fewer than two times during the pre- or the post- period. As a result, 257 patients were excluded, and data of the remaining 705 patients and a total of 3,678 blood test records were then analyzed.

We used the HbAlc measurement based on the National Glycohemoglobin Standardization Program (NGSP). The NGSP is routinely applied in many other countries [22, 27, $28,29]$. In Japan, the HbA1c measurement based on the Japan Diabetes Society (JDS) had been used until March 31, 2012 and the NGSP has been used since April 1, 2012. The conversion equation from the JDS to NGSP is as follows: $\operatorname{NGSP}(\%)=\operatorname{JDS}(\%)+0.4 \%[22,30]$.

\subsection{Analysis}

Primary outcome measures included $\mathrm{HbAlc}$, fasting blood glucose, LDL-C, and eGFR. These were averaged for each patient within the pre- and post- periods, and compared using the Wilcoxon signed-rank test. First, we analyzed the overall data. Second, we compared the data among severitystratified groups. We stratified the patients into two groups, based on the baseline, into severe (e.g., HbAlc level $\geq 8.4 \%$ [8.0\% JDS]) and moderate groups (e.g., HbAlc level $<8.4 \%$ [8.0\% JDS]). Furthermore, we analyzed correlations between pre-intervention (baseline) and difference during pre- and post- intervention with the Pearson's correlation coefficient. We adapted a 5\%, two-tailed significance level. R 3.0.2 software ( $\mathrm{R}$ Foundation for Statistical Computing, Vienna, Austria) was used for all statistical analyses. As for the participant consent, the documentation of informed consent was waived by the institutional review board (IRB) of Tokyo Medical and Dental University. Based on ethical guidelines for epidemiological research presented by the Ministry of Health, Labour and Welfare, we employed an opt-out methodology to obtain the participants. The study protocol and informed consent procedure were approved by the institutional review boards of Tokyo Medical and Dental University.

Table 1: Patient characteristics of $\mathrm{HbAlc}$ levels before the introduction.

\begin{tabular}{|c|c|c|c|c|}
\hline \multirow{3}{*}{ Characteristics } & \multicolumn{4}{|c|}{ Mean HbAlc levels in the pre- period } \\
\hline & \multirow{2}{*}{\multicolumn{2}{|c|}{$\begin{array}{l}<8.4 \%^{9}(\mathrm{n}=470) \\
\text { Median }(\mathrm{IQR})\end{array}$}} & \multirow{2}{*}{\multicolumn{2}{|c|}{$\begin{array}{l}\geq 8.4 \%^{\circ}(\mathrm{n}=235) \\
\text { Median }(\mathrm{IQR})\end{array}$}} \\
\hline & & & & \\
\hline Age & 67 & $(60-76)$ & 64 & $(55-73)$ \\
\hline $\operatorname{Sex}^{*}($ Female $)$ & 276 & $(58.7)$ & 138 & $(58.7)$ \\
\hline Fasting blood glucose level (mg/dl) & 169 & $(148-194)$ & 217 & $(182-260)$ \\
\hline $\operatorname{eGFR}\left(\mathrm{mL} / \mathrm{min} / 1.73 \mathrm{~m}^{2}\right)$ & 73.2 & $(61.2-88.3)$ & 81.8 & $(62.4-96.6)$ \\
\hline $\mathrm{LDL}-\mathrm{C}(\mathrm{mg} / \mathrm{dl})$ & 95 & $(77-116)$ & 98 & $(84-119)$ \\
\hline
\end{tabular}

HbAlc, glycated hemoglobin; eGFR, estimated glomerular filtration rate; LDL-C, low-density lipoprotein cholesterol; IQR, interquartile range. gHbAlc measurement based on the National Glycohemoglobin Standardization Program (NGSP). *Sex is showed as number and percentage. 


\section{Results}

\subsection{Baseline Characteristics}

Baseline characteristics are shown in Table 1. Briefly, 55.5\% of patients were $\geq 65$ years old and $26.8 \%$ of patients were $\geq 75$ years old. There were 414 female patients (58.7\%). The laboratory parameters are also listed in Table 1 . Of 705 patients, 235 patients (33.3\%) had a baseline HbA1c level of $\geq 8.4 \%$ (8.0\% JDS). In addition, 497 patients (70.5\%) had baseline fasting blood glucose levels $\geq 160 \mathrm{mg} / \mathrm{dl}$. Forty-nine patients (7.0\%) had baseline LDL-C levels $\geq 140 \mathrm{mg} / \mathrm{dl}$, and 156 patients (22.1\%) had baseline eGFR $<60 \mathrm{~mL} / \mathrm{min} / 1.73 \mathrm{~m}^{2}$.

\subsection{Patient Outcomes}

A total number of 3,678 blood test results from 705 patients were analyzed. The mean of the test frequency per

Table 2: Comparison diabetic patients' outcomes six months before and after the introduction of the CDSS.

\begin{tabular}{|c|c|c|c|c|}
\hline Laboratory values & Pre-introduction & Post-introduction & $P$ value ${ }^{*}$ & Cohen's $d$ \\
\hline \multicolumn{5}{|l|}{ HbAlc (\%) } \\
\hline All $(\mathrm{n}=705)$ & & & $<0.001^{\ddagger}$ & 0.175 \\
\hline Mean \pm SD & $8.23 \pm 1.15$ & $8.04 \pm 1.01$ & & \\
\hline Median (IQR) & $7.90(7.45-8.68)$ & $7.77(7.33-8.50)$ & & \\
\hline$<8.4$ NGSP $(8.0$ JDS $)(\mathrm{n}=470)$ & & & $0.025^{\dagger}$ & 0.158 \\
\hline Mean \pm SD & $7.61 \pm 0.40$ & $7.70 \pm 0.65$ & & \\
\hline Median (IQR) & $7.60(7.27-7.90)$ & $7.55(7.20-7.98)$ & & \\
\hline$\geq 8.4$ NGSP (8.0 JDS) $(\mathrm{n}=235)$ & & & $<0.001^{\ddagger}$ & 0.642 \\
\hline Mean \pm SD & $9.49 \pm 1.13$ & $8.73 \pm 1.23$ & & \\
\hline Median (IQR) & $9.09(8.68-9.95)$ & $8.61(7.87-9.20)$ & & \\
\hline \multicolumn{5}{|l|}{ Fasting blood glucose level(mg/dl) } \\
\hline All $(\mathrm{n}=705)$ & & & 0.28 & 0.032 \\
\hline Mean \pm SD & $191.7 \pm 49.8$ & $190.1 \pm 51.0$ & & \\
\hline Median (IQR) & $180.0(155.0-214.7)$ & $178.6(151.5-216.5)$ & & \\
\hline$<160(\mathrm{n}=208)$ & & & $<0.001^{\ddagger}$ & 0.613 \\
\hline Mean \pm SD & $144.2 \pm 9.2$ & $165.2 \pm 37.9$ & & \\
\hline Median (IQR) & $144.7(137.0-152.0)$ & $153.6(141.5-178.6)$ & & \\
\hline$\geq 160(\mathrm{n}=497)$ & & & $<0.001^{\ddagger}$ & 0.224 \\
\hline Mean \pm SD & $211.6 \pm 46.2$ & $200.5 \pm 52.2$ & & \\
\hline Median (IQR) & $199.3(177.5-231.0)$ & $189.8(161.5-231.0)$ & & \\
\hline \multicolumn{5}{|l|}{ eGFR $\left(\mathrm{ml} / \mathrm{min} / 1.73 \mathrm{~m}^{2}\right)$} \\
\hline All $(\mathrm{n}=687)$ & & & $<0.001^{\ddagger}$ & 0.097 \\
\hline Mean \pm SD & $76.8 \pm 25.6$ & $74.3 \pm 25.8$ & & \\
\hline Median (IQR) & $75.6(61.6-92.1)$ & $73.4(58.9-89.2)$ & & \\
\hline$\geq 60(\mathrm{n}=531)$ & & & $<0.001^{\ddagger}$ & 0.874 \\
\hline Mean \pm SD & $85.9 \pm 20.7$ & $83.0 \pm 21.5$ & & \\
\hline Median (IQR) & $82.7(71.3-95.7)$ & $80.0(68.8-92.8)$ & & \\
\hline$<60(\mathrm{n}=156)$ & & & $0.004^{\dagger}$ & 0.064 \\
\hline Mean \pm SD & $45.6 \pm 13.1$ & $44.7 \pm 15.0$ & & \\
\hline Median (IQR) & $50.3(39.6-55.4)$ & $47.2(37.5-55.6)$ & & \\
\hline \multicolumn{5}{|l|}{ LDL-C (mg/dl) } \\
\hline All $(\mathrm{n}=635)$ & & & $<0.001^{*}$ & 0.148 \\
\hline Mean \pm SD & $99.7 \pm 29.2$ & $95.4 \pm 28.8$ & & \\
\hline Median (IQR) & $97.0(78.7-117.0)$ & $93.0(75.5-114.0)$ & & \\
\hline$<140(\mathrm{n}=586)$ & & & $<0.001^{\ddagger}$ & 0.120 \\
\hline Mean \pm SD & $94.5 \pm 22.9$ & $91.9 \pm 20.3$ & & \\
\hline Median (IQR) & $94.3(77.0-112.5)$ & $91.0(74.0-110.0)$ & & \\
\hline$\geq 140(\mathrm{n}=49)$ & & & $<0.001^{\ddagger}$ & \\
\hline Mean \pm SD & $161.8 \pm 23.3$ & $136.2 \pm 26.7$ & & \\
\hline Median (IQR) & $155.4(145.3-167.5)$ & $136.8(119.6-152.0)$ & & \\
\hline
\end{tabular}

HbA1c, glycated hemoglobin; eGFR, estimated glomerular filtration rate; LDL-C, low-density lipoprotein cholesterol; NGSP, National Glycohemoglobin Standardization Program; JDS, Japan Diabetes Society; SD, standard deviation; IQR, interquartile range. ${ }^{\star}$ Wilcoxon signed rank test; $\dagger$ p-value $<0.05$; p-value $<0.001$. 
person was 5 (3-6) times during the pre- and the post- periods. Results are given for the group as an overall and stratified by severe and moderate cases. Continuous variables are summarized as mean \pm standard deviation (SD) and median with interquartile range (IQR) values. These results are shown in Table 2.

The mean HbA1c levels among severe cases (baseline $\geq 8.4 \%$ ) improved significantly over the study period, from $9.49 \pm 1.13 \%$ to $8.73 \pm 1.23 \%(\mathrm{p}<0.001$, Cohen's $d=0.642)$. In contrast, the moderate group (baseline $<8.4 \%$ ) deteriorated significantly ( $\mathrm{p}=$ 0.025 , Cohen's $d=0.158$ ), from $7.61 \pm 0.40 \%$ to $7.70 \pm 0.65 \%$. Because the effect size of 0.3 (i.e., 0.3 SD of the baseline score) was used as the MCID in this study, the difference was not important clinically. In terms of fasting blood glucose levels, the severe group (baseline $\geq 160 \mathrm{mg} / \mathrm{dl}$ ) improved significantly ( $\mathrm{p}<0.001$, Cohen's $d=0.224)$, from $211.6 \pm 46.2 \mathrm{mg} / \mathrm{dl}$ to $200.5 \pm 52.2 \mathrm{mg} /$ dl. On the contrary, the moderate group (baseline $<160 \mathrm{mg} / \mathrm{dl}$ ) significantly deteriorated, from $144.2 \pm 9.2 \mathrm{mg} / \mathrm{dl}$ to $165.2 \pm 37.9$ $\mathrm{mg} / \mathrm{dl}$ ( $\mathrm{p}<0.001$, Cohen's $d=0.613$ ). Figure 3 depicts correlations between the mean $\mathrm{HbAlc}$ in the pre-period and the difference of HbA1c during the pre- and the post- period. The Pearson's correlation coefficient was -0.56 (95\% confidence interval [CI] -0.60 to $-0.50, \mathrm{p}<0.001)$. The greater $\mathrm{HbAlc}$ level in the preperiod was associated with a greater reduction. S1 and S2 Figures show equivalence tests for comparing correlation coefficients between all patients and patients outside the boundary (i.e., those whose HbA1c levels were $8.4 \pm 0.3 \%$ in the pre- period). In the severe group, the correlation coefficients of all patients and patients outside the boundary were -0.47 (95\%CI -0.56 to -0.36$)$ and -0.42 (95\%CI -0.53 to -0.29$)$, respectively $(\rho=-0.45)$. As for the moderate group, the correlation coefficients of all patients and patients outside the boundary were -0.24 (95\%CI -0.32 to -0.15$)$ and -0.18 (95\%CI -0.28 to -0.08$)$, respectively $(\rho=-0.21)$.

\section{Discussion}

\subsection{Diabetic Patients' Outcomes with the CDSS}

To compare diabetic patients' outcomes six months before and after the introduction of the CDSS, we considered 705 patients in the general hospital and ten clinics that embedded the CDSS within EHRs in April 2011, and tracked their medical records from October 2010 to March 2012 (split at April 2011; pre- and post- period). A total number of 3,678 blood test results were analyzed. The mean HbAlc levels among severe cases (HbAlc $\geq 8.4 \%$ in the pre-period) were significantly improved over the study period $(\mathrm{p}<0.001)$. In contrast, the moderate group ( $\mathrm{HbAlc}$ $<8.4 \%$ in the pre- period) deteriorated significantly $(\mathrm{p}=0.025)$, but the difference was not important clinically.

Improvements of patients outcomes were observed, indicating the potential effectiveness of the CDSS. The CDSS mainly had two functions: (1) visually highlight abnormal laboratory values on longitudinal inspection data; and (2) to provide a list of patients with severe diabetes. In the empirical study, HbA1c values were highlighted when the values exceeded

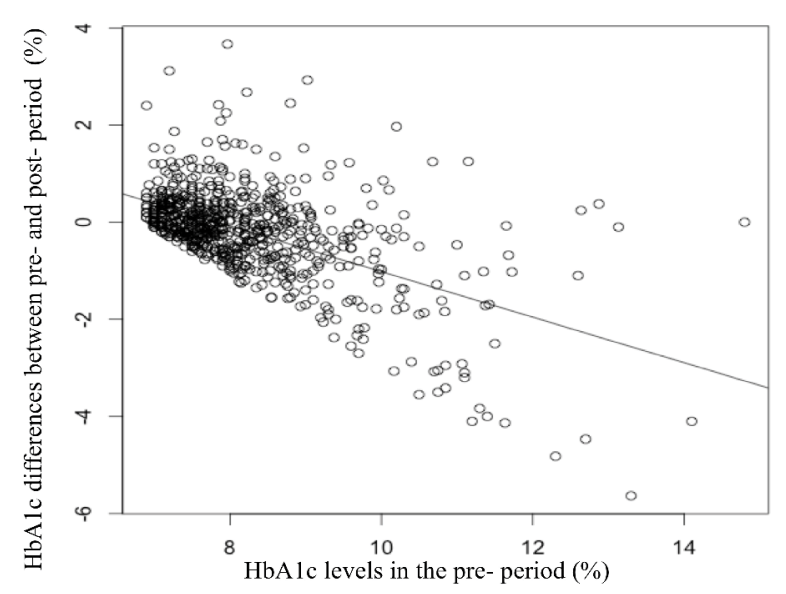

Figure 3: Correlations between the baseline $\mathrm{HbAlc}$ and the difference of HbAlc during pre- and post- period.

Correlations between the $\mathrm{HbAlc}$ in the pre- period and the difference in $\mathrm{HbAlc}$ between the pre- and the post- period. The Pearson's correlation coefficient is $-0.56(95 \% \mathrm{CI}-0.60$ to $-0.50, \mathrm{p}<0.001)$.

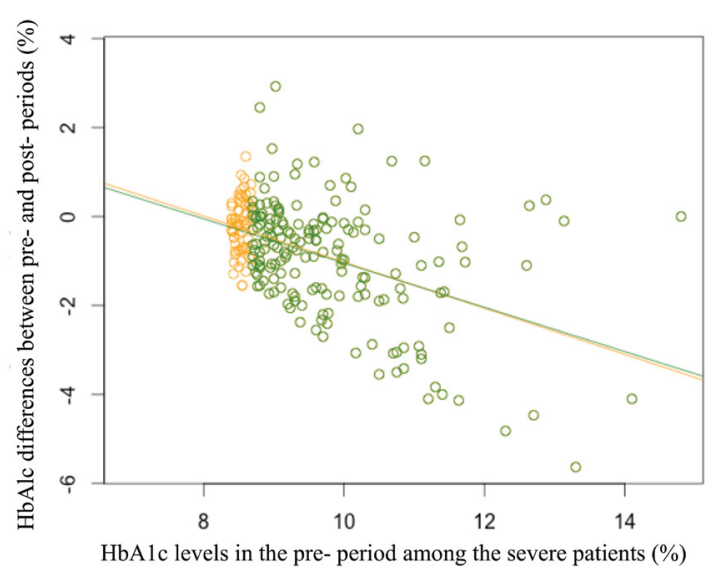

S1 Figure: Correlations between the HbAlc in the pre- period and the difference of $\mathrm{HbAlc}$ during the pre- and the postperiods among the severe patients.

Correlations between the HbAlc in the pre- period and the difference in $\mathrm{HbAlc}$ between the pre- and the post- period among the severe patients. The correlation coefficients of all patients and patients outside the boundary (i.e., $8.4 \% \leq \mathrm{HbA} 1 \mathrm{c}<8.7 \%$ in the pre- period) were -0.47 $(95 \% \mathrm{CI}-0.56$ to -0.36$)$ and $-0.42(95 \% \mathrm{CI}-0.53$ to -0.29$)$, respectively $(\rho=-0.45)$.

$8.4 \%$ based on the treatment guideline. Therefore, the values of the severe patients ( $\mathrm{HbAlc} \geq 8.4 \%$ in the pre- period) were more often highlighted than the moderate patients (HbAlc $<8.4 \%$ in the pre- period). Through repeated notifications, the CDSS has more opportunity to improve patients' outcomes of diabetes care. According to a study in US, diabetes care practice often does not achieve recommended diabetes care standards [31]. In that case, the repeated notifications may contribute to treatment decisions and to increase adherence to recommended diabetes care, although the mechanism remains unclear. Through interviews, some practitioners stated that the overlooking of deterioration of 


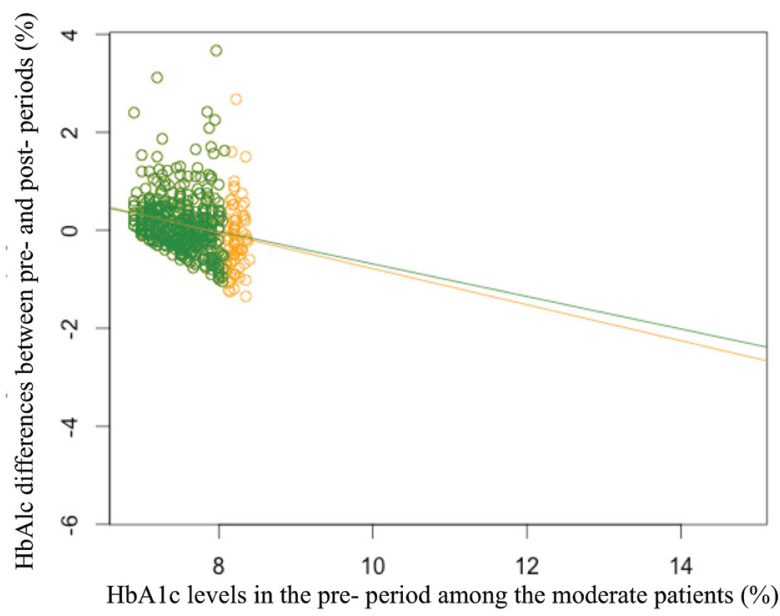

S2 Figure: Correlations between the HbAlc in the pre- period and the difference of $\mathrm{HbAlc}$ during the pre- and the post- periods among the moderate patients.

Correlations between the HbAlc in the pre- period and the difference in $\mathrm{HbAlc}$ between the pre- and the post- period among the moderate patients. The correlation coefficients of all patients and patients outside the boundary (i.e., $8.1 \% \leq \mathrm{HbAlc}<8.4 \%$ in the pre- period) were $-0.24(95 \% \mathrm{CI}-0.32$ to $-0.15)$ and $-0.18(95 \% \mathrm{CI}-0.28$ to -0.08$)$, respectively $(\rho=-0.21)$.

inspection items was almost eliminated and it became easier for practitioners to follow the treatment guideline. Further research into how the repeated notifications contribute to treatment decisions is needed to establish stronger evidence.

We also compared the two groups (i.e., severe and moderate groups) on the correlation between the mean $\mathrm{HbAlc}$ in the preperiod and the difference of $\mathrm{HbAlc}$ during the pre- and the postperiod. Pearson's product-moment correlations in the severe and moderate groups were -0.47 and -0.24 respectively. Furthermore, we conducted an equivalence test for comparing correlation coefficients between the severe and moderate groups $(\mathrm{p}<0.001)$. In the severe group, whose values were highlighted more often by the CDSS, the HbAlc values significantly improved, so the CDSS might contribute to improve patients' outcomes. However, there was the possibility of regression to the mean because of a lack of control group. In a future round of the empirical study, we plan to quantify the effect of the CDSS with a control group.

Previous studies shown mixed effects on patients' outcomes after the introduction of a CDSS. In a randomized trial in primary care clinics in Canada, individualized electronic decision support and reminders improved diabetes care [12]. The mean followup was 5.9 months and the main outcomes were $\mathrm{HbAlc}$, blood pressure, and LDL-C. The CDSS improved the process of care and some clinical markers of diabetes care. In US, several studies of diabetes care with a CDSS have been conducted during the past two decades. One of the studies was conducted in primary care 6 and examined three outcomes (i.e., HbAlc, LDL-C, and blood pressure) at the 6-month follow-up [32]. The research found that the CDSS significantly improved HbAlc and some aspects of blood pressure. On the other hand, a review paper suggested that the use of a CDSS resulted in only modest improvements in quality of diabetes care and further empirical studies were needed [5]. To date, very little experimental work has been done on the effectiveness of a CDSS and little is known about whether a CDSS could contribute to patients' outcomes. This study contributes important insights about the effectiveness of a CDSS on diabetes care in Japan.

\subsection{Limitations of the Study}

Several limitations of this study should be acknowledged. First, the results with the empirical study are generalizable only to similar settings. Although similar evaluation methods are used in many settings in software engineering and medical informatics literature [33,34], setting up a control group would have improved the quality of this study. Second, there is the possibility that observed changes represented regression toward the mean because of the lack of a control group. Against the interpretation, note that we used several laboratory values to compute the mean of $\mathrm{HbA1c}$ levels in the periods. The mean of the test frequency per person was 5 (3-6) times during the pre- and the post- periods. Furthermore, to reduce measurement error, we conducted equivalence tests for comparing correlation coefficients (i.e., HbAlc levels were $8.4 \pm 0.3 \%$ in the pre- period). From these results, the population correlation coefficients of all patients and patients outside the boundary were not different. Third, there is a possibility of other factors that may affect patients' outcomes (e.g., changes of treatment plan with the passage of time) and the Hawthorne effect. Despite these limitations, the findings of this study provide useful information regarding the advantages of using the CDSS in clinical practice.

\section{Conclusion}

To compare diabetic patients' outcomes six months before and after the introduction of the CDSS, we studied 705 patients in the general hospital and ten clinics that embedded the CDSS within EHRs in April 2011, and tracked their medical records from October 2010 to March 2012. After the introduction of the CDSS, the mean HbAlc levels among severe cases were significantly improved over the study period $(p<0.001)$. In contrast, the moderate group deteriorated significantly $(p=0.025)$. Improvements of patients' outcomes were observed, indicating the potential effectiveness of the CDSS. Visually emphasizing abnormal laboratory values and displaying severe patients may be an effective way for disease control of diabetes patients.

\section{Acknowledgement}

Gratitude is expressed to the staff at the Chiba Prefectural Togane Hospital for providing and collecting the laboratory data, and to Tomoyasu Tanaka at NTT DATA Corporation for technical assistance. 


\section{Author Contribution}

All others have contributed substantially to the conception and design, occasion of data, or analysis; S. Ota has drafted the article; S. Ota and A. Hirai performed the data collection of participants; S. Ota and K. Mogushi performed the statistical analysis for the patient outcomes; S. Ota, K. Mogushi, and A. Hirai performed the interpretation the data; K. Mogushi, Y. Niimura, and H. Tanaka revised the article critically for important intellectual content; All authors have given approval of the final version to be published.

\section{Financial Disclosure}

This work was supported by Health Labour Sciences Research Grant project for research on region medical: matching fund subsidy from Ministry of Health Labour and Welfare in Japan. The funders had no role in study design, data collection and analysis, decision to publish, or preparation of the manuscript.

\section{Competing Interests}

The authors have declared that no competing interests exist.

\section{References}

[1] World Health Organization. Global report on diabetes. Geneva: WHO Press; 2016.

[2] http://www.mhlw.go.jp/english/database/db-hss/sps_2014.html

[3] Coiera E. Guide to health informatics. $3^{\text {rd }}$ ed. United States: CRC Press; 2015.

[4] Nguyen L, Bellucci E, Nguyen LT. Electronic health records implementation: an evaluation of information system impact and contingency factors. Int J Med Inform. 2014; 83: 779-796.

[5] Ali SM, Giordano R, Lakhani S, Walker DM. A review of randomized controlled trials of medical record powered clinical decision support system to improve quality of diabetes care. Int J Med Inform. 2016; 87: 91-100.

[6] Lau F, Price M, Boyd J, Partridge C, Bell H, Raworth R. Impact of electronic medical record on physician practice in office settings: a systematic review. BMC Med Inform Decis Mak. 2012; 12:10.

[7] Wu RC, Straus SE. Evidence for handheld electronic medical records in improving care: a systematic review. BMC Med Inform Decis Mak. 2006; 6: 26.

[8] Smith AJ, Skow A, Bodurtha J, Kinra S. Health information technology in screening and treatment of child obesity: a systematic review. Pediatrics. 2013; 131: e894-902.

[9] World Health Organization. mHealth: New horizons for health through mobile technologies: second global survey on eHealth. Geneva: WHO Press; 2011.

[10] World Health Organization. Legal frameworks for eHealth: based on the findings of the second global survey on eHealth. Geneva: WHO Press; 2012

[11] Cebul RD, Love TE, Jain AK, Hebert CJ. Electronic health records and quality of diabetes care. N Engl J Med. 2011; 365: 825-33.
[12] Holbrook A, Thabane L, Keshavjee K, Dolovich L, Bernstein $\mathrm{B}$, Chan $\mathrm{D}$, et al. Individualized electronic decision support and reminders to improve diabetes care in the community: COMPETE II randomized trial. CMAJ. 2009; 181: 37-44.

[13] Crosson JC, Ohman-Strickland PA, Cohen DJ, Clark EC, Crabtree BF. Typical electronic health record use in primary care practices and the quality of diabetes care. Ann Fam Med. 2012; 10: 221-227.

14] Balas EA, Krishna S, Kretschmer RA, Cheek TR, Lobach DF, Boren SA. Computerized knowledge management in diabetes care. Med Care. 2004; 42: 610-621.

[15] International Telecommunication Union. Be He@lthy, Be Mobile. Geneva: 2014.

[16] Osheroff J, Teich J, Levick D, Saldana L, Velasco F, Sittig D, et al. Improving Outcomes with Clinical Decision Support: An Implementer's Guide. $2^{\text {nd }}$ ed. HIMSS; 2012.

[17] Samal L, Linder JA, Lipsitz SR, Hicks LS. Electronic health records, clinical decision support, and blood pressure control. Am J Manag Care. 2011; 17: 626-632.

[18] Moja L, Kwag KH, Lytras T, Bertizzolo L, Brandt L, Pecoraro V, et al. Effectiveness of computerized decision support systems linked to electronic health records: a systematic review and meta-analysis. Am J Public Health. 2014; 104: e12-e22.

[19] Jaspers MW, Smeulers M, Vermeulen H, Peute LW. Effects of clinical decision-support systems on practitioner performance and patient outcomes: a synthesis of high-quality systematic review findings. J Am Med Inform Assoc. 2011; 18: 327-34.

[20] Garg AX, Adhikari NK, McDonald H, Rosas-Arellano MP, Devereaux PJ, Beyene J, et al. Effects of computerized clinical decision support systems on practitioner performance and patient outcomes: a systematic review. JAMA. 2005; 293: 12231238 .

[21] Chaudhry B, Wang J, Wu S, Maglione M, Mojica W, Roth E, et al. Systematic review: impact of health information technology on quality, efficiency, and costs of medical care. Ann Intern Med. 2006; 144: 742-752.

[22] Seino Y, Nanjo K, Tajima N, Kadowaki T, Kashiwagi A, Araki $\mathrm{E}$, et al. Report of the committee on the classification and diagnostic criteria of diabetes mellitus. J Diabetes Investig. 2010; $1: 212-228$.

[23] The Japan Diabetes Society. Treatment Guide for Diabetes 2007. Tokyo: Bunkodo; 2007.

[24] The Japan Diabetes Society. Evidence-based Practice Guideline for the Treatment for Diabetes in Japan 2013. Tokyo: Nunkodo; 2013.

[25] Faul F, Erdfelder E, Lang AG, Buchner A. G*Power 3: a flexible statistical power analysis program for the social, behavioral, and biomedical sciences. Behav Res Methods. 2007; 39: 175-91.

[26] Nathan DM, Turgeon H, Regan S. Relationship between glycated haemoglobin levels and mean glucose levels over time. Diabetologia. 2007; 50: 2239-2244.

[27] World Health Organization. Use of Glycated Haemoglobin (HbA1c) in the Diagnosis of Diabetes Mellitus: Abbreviated Report of a WHO Consultation. Geneva: WHO Press; 2011. 
[28] Amemiya S, Hoshino T. The worldwide standardization of hemoglobin A1c measurement: the current statement from the Japan Diabetes Society and the issues to be solved. Rinsho Byori. 2013; 61: 594-601.

[29] Kashiwagi A. Development of the HbAlc international standardization of HbAlc measurement in Japan Diabetes Society. Rinsho Byori. 2013; 61: 585-593.

[30] Kashiwagi A, Kasuga M, Araki E, Oka Y, Hanafusa T, Ito H, et al. International clinical harmonization of glycated hemoglobin in Japan: From Japan Diabetes Society to National Glycohemoglobin Standardization Program values. J Diabetes Investig. 2012; 3: 39-40.

[31] McGlynn EA, Asch SM, Adams J, Keesey J, Hicks J, DeCristofaro A, et al. The quality of health care delivered to adults in the United States. N Engl J Med. 2003; 348: 2635-2645.
[32] O'Connor PJ, Sperl-Hillen JM, Rush WA, Johnson PE, Amundson GH, Asche SE, et al. Impact of electronic health record clinical decision support on diabetes care: a randomized trial. Ann Fam Med. 2011; 9: 12-21.

[33] Kampenes VB, Dyba T, Hannay JE, Sjoberg DIK. A systemetic review of quasi-experiments in software engineering. Information and Software Technology. 2009; 51: 71-82.

[34] Harris AD, McGregor JC, Perencevich EN, Furuno JP, Zhu $\mathrm{J}$, Peterson DE, et al. The use and interpretation of quasiexperimental studies in medical informatics. J Am Med Inform Assoc. 2006; 13: 16-23. 